\title{
Response to the Food and Drug Administration warning on the use of anaesthetics in young children
}

Silky Wong, FHKAM (Anaesthesiology), FANZCA, Theresa WC Hui *, FHKAM (Anaesthesiology), FANZCA Department of Anaesthesiology, Queen Mary Hospital, Pokfulam, Hong Kong

Hong Kong Med J 2017;23:433-4

* huiwct@ha.org.hk DOI: 10.12809/hkmj176918

On 14 December 2016, the US Food and Drug Administration (FDA) issued a warning that the repeated or lengthy use of general anaesthetic and sedative drugs in children under 3 years old and in pregnant women in their third trimester may affect the development of children's brains. Warning labels were required to be added to general anaesthetic and sedative drugs. ${ }^{1}$

Data from published studies in pregnant and young animals have shown that the use of general anaesthetics increases the chance of apoptosis and neurodegeneration in the developing brain. Persistent memory and learning disabilities have been demonstrated ${ }^{2,3}$ as well as increased severity with increasing duration of anaesthesia. ${ }^{4}$ Certain human studies suggest an association between anaesthesia and subsequent behaviour or learning issues such as autism, attention-deficit disorder, and language deficits..$^{5-7}$ Some researchers postulate that even relatively simple anaesthesia of babies and young children can pose a risk of neurotoxicity. The question is whether or not we can translate such animal data to humans and to what extent we should interpret the animal findings. ${ }^{8}$

For many years well-designed human studies were lacking. Data were mainly observational and retrospective, and with too many confounding factors. There were often conflicting results in different studies.9,10 Recently, however, more robust human studies have been published such as General Anaesthesia compared to Spinal anaesthesia (GAS) study ${ }^{11}$ and Pediatric Anesthesia NeuroDevelopment Assessment (PANDA). ${ }^{12,13}$ The GAS study, which compares children less than 60 weeks' post-gestational age (but older than 26 weeks' post gestation) undergoing hernia surgery under either general anaesthesia or awake regional anaesthesia, has shown that at the 2-year mark (secondary outcome), there is no increase in risk of learning disability. This study is ongoing with its primary outcome being the Wechsler Preschool and Primary Scale of Intelligence Third Edition Full Scale Intelligence Quotient score at 5 years old. The PANDA study was a sibling-matched cohort observational study that examined whether anaesthesia exposure in healthy children younger than 3 years old is associated with an increased risk of impaired global cognitive function as the primary outcome. Their secondary outcome was abnormal domain-specific neurocognitive function and behaviour at the ages of 8 to 15 years. The study found no significant difference between the exposed and unexposed in terms of both primary and secondary outcomes. Both studies point towards a slightly more reassuring outlook for short-duration exposure to anaesthesia in children.

Although a FDA warning on anaesthesia and exposure to anaesthetic drugs in paediatric, neonatal, and third-trimester pregnant women has been long expected, the timing of this warning came as a surprise to many in the paediatric anaesthesia community, particularly in light of the recent findings of the more sanguine and robust human studies and no new evidence of detrimental effects of anaesthesia.

Moreover, the FDA uses a cut-off age of 3 years old. This age limit is highly debatable since there is currently no evidence to support the use of 3 years as a cut-off or that anaesthesia in infants older than 3 years will not be harmful; and vice versa. Some use 3 years as a cut-off for the period of rapid neurodevelopment in a child; nonetheless a few retrospective cohort studies point towards anaesthesia affecting children of an older agegroup. ${ }^{14,15}$ Many of these concerns are likely to be applicable to all patients undergoing surgery with those at the extremes of age being more vulnerable. Duration of surgery and the extent of tissue trauma, need for blood transfusion, and the choice of anaesthetic agent are also important variables.

Data from the American Society of Anesthesiologists (ASA) Closed Claims Project were analysed and revealed that children under 1 year of age with associated disease were at increased risk of major and minor morbidity. ${ }^{16}$ Cardiac arrests related to anaesthesia most often occurred in infants who were ASA status 3 to 5 and undergoing emergency procedures. Paediatric anaesthesiologists should therefore collaborate with surgeons to determine the best time for surgery in a child. ${ }^{17}$ Often, children need anaesthesia for operations or procedures that should not be delayed. In these cases, it is easier to balance the detrimental effects of not having the surgery against the potential risk of anaesthesia. In 
non-urgent surgeries that will not affect the child or the outcome of the operation if postponed until later in life, it is reasonable to discuss with all parties involved, including their parents or guardians, as to whether deferring the surgery can be considered in very young children. Given that perioperative complications are more common in the very young, ${ }^{18}$ this is a good general principle that has always been advocated by those involved in perioperative paediatric care, notwithstanding this FDA warning.

\section{References}

1. FDA Drug Safety Communication: FDA review results in new warnings about using general anesthetics and sedation drugs in young children and pregnant women. Available from: https://www.fda.gov/Drugs/DrugSafety/ucm532356. htm. Accessed Jul 2017.

2. Jevtovic-Todorovic V, Hartman RE, Izumi Y, et al. Early exposure to common anesthetic agents causes widespread neurodegeneration in the developing rat brain and persistent learning deficits. J Neurosci 2003;23:876-82.

3. Vutskits L, Xie Z. Lasting impact of general anaesthesia on the brain: mechanisms and relevance. Nat Rev Neurosci 2016;17:705-17.

4. Zou X, Patterson TA, Divine RL, et al. Prolonged exposure to ketamine increases neurodegeneration in the developing monkey brain. Int J Dev Neurosci 2009;27:727-31.

5. Hansen TG. Anesthesia-related neurotoxicity and the developing animal brain is not a significant problem in children. Paediatr Anaesth 2015;25:65-72.

6. Ing $\mathrm{C}$, DiMaggio $\mathrm{C}$, Whitehouse $\mathrm{A}$, et al. Long-term differences in language and cognitive function after childhood exposure to anesthesia. Pediatrics 2012;130:e47685.

7. Ing $\mathrm{CH}$, DiMaggio $\mathrm{CJ}$, Malacova $\mathrm{E}$, et al. Comparative analysis of outcome measures used in examining neurodevelopmental effects of early childhood anesthesia exposure. Anesthesiology 2014;120:1319-32.
8. Todd MM. Anesthetic neurotoxicity: the collision between laboratory neuroscience and clinical medicine. Anesthesiology 2004;101:272-3.

9. Hansen TG, Pedersen JK, Henneberg SW, et al. Academic performance in adolescence after inguinal hernia repair in infancy: a nationwide cohort study. Anesthesiology 2011;114:1076-85

10. Hansen TG, Pedersen JK, Henneberg SW, Morton NS, Christensen K. Educational outcome in adolescence following pyloric stenosis repair before 3 months of age: a nationwide cohort study. Paediatr Anaesth 2013;23:883-90.

11. Davidson AJ, Disma N, de Graaff JC, et al. Neurodevelopmental outcome at 2 years of age after general anaesthesia and awake-regional anaesthesia in infancy (GAS): an international multicentre, randomised controlled trial. Lancet 2016;387:239-50.

12. Sun LS, Li G, Miller TL, et al. Association between a single general anesthesia exposure before age 36 months and neurocognitive outcomes in later childhood. JAMA 2016;315:2312-20.

13. Chinn GA, Sasaki Russell JM, Sall JW. Is a short anesthetic exposure in children safe? Time will tell: a focused commentary of the GAS and PANDA trials. Ann Transl Med 2016;4:408.

14. Graham MR, Brownell M, Chateau DG, Dragan RD, Burchill C, Fransoo RR. Neurodevelopmental assessment in kindergarten in children exposed to general anesthesia before the age of 4 years: a retrospective matched cohort study. Anesthesiology 2016;125:667-77.

15. O'Leary JD, Janus M, Duku E, et al. A population-based study evaluating the association between surgery in early life and children development at primary school entry. Anesthesiology 2016;125:272-9.

16. Jimenez N, Posner KL, Cheney FW, Caplan RA, Lee LA, Domino KB. An update on pediatric anesthesia liability: a closed claims analysis. Anesth Analg 2007;104:147-53.

17. Paterson N, Waterhouse P. Risk in paediatric anesthesia. Pediatr Anaesth 2011;21:848-57.

18. Weiss M, Hansen TG, Engelhardt T. Ensuring safe anaesthesia for neonates, infants and young children: what really matters. Arch Dis Child 2016;101:650-2. 